Research paper

\title{
Synthesis and property evaluations of highly filled polyimide composites under thermal cycling conditions from $-190{ }^{\circ} \mathrm{C}$ to $+200{ }^{\circ} \mathrm{C}$
}

\author{
N.I. Cherkashina ${ }^{\mathrm{a}, *}$, V.I. Pavlenko ${ }^{\mathrm{a}}$, A.V. Noskov ${ }^{\mathrm{b}}$ \\ ${ }^{a}$ Belgorod State Technological University Named After V.G. Shoukhov, Kostyukov str., 46, Belgorod 308012, Russia \\ ${ }^{\mathrm{b}}$ Belgorod State National Research University, Pobedy str., 85, Belgorod 308015, Russia
}

\section{A R T I C L E I N F O}

\section{Keywords:}

Polyimide composites

Modification

Cryogenic temperature

Thermal cycling

Tensile strength

\begin{abstract}
A B S T R A C T
This paper presents data on the synthesis of composites based on polyimide and modified tungsten (IV) oxide $\left(\mathrm{WO}_{2}\right)$. The resulting, highly filled, polyimide $/ \mathrm{WO}_{2}$ composites were investigated by electron microscopy and thermal analysis in a gas environment of oxygen and argon. The maximum content of modified $\mathrm{WO}_{2}$, in the studied composites, was $60 \mathrm{wt} \%$. The introduction of $\mathrm{WO}_{2}$ increases the thermal stability of the composites. For pure polyimide, the upper limit of the operating temperature is $507{ }^{\circ} \mathrm{C}$; for a composite with a content of $30 \mathrm{wt} \%$ $\mathrm{WO}_{2}-526^{\circ} \mathrm{C}$, and for $60 \mathrm{wt} \% \mathrm{WO}_{2}-554^{\circ} \mathrm{C}$ in a gas environment of Ar. The change in the physico-mechanical properties of highly filled polyimide composites was studied under the conditions of thermal cycling from $-190^{\circ} \mathrm{C}$ to $+200^{\circ} \mathrm{C}$. The time of one cycle was $22 \mathrm{~min}$. The thermal cycle was repeated 5, 10 and 20 times. The following parameters were determined: tensile strength, modulus of tensile elasticity and elongation under tension. The introduction of $\mathrm{WO}_{2}$ slightly reduces the initial strength characteristics of the composites.
\end{abstract}

\section{Introduction}

It is unthinkable to consider modern aerospace technology without polymer composite materials. Traditionally, for space flight applications, mainly aluminum and titanium alloys are used [1-3]. However, despite the high strength and performance characteristics of metal alloys, their use significantly increases the weight of the payload of the aircraft. In addition, the use of metal alloys leads to the appearance of bremsstrahlung X-rays, caused by the impact of protons and electrons of the Earth's radiation belts on the atoms of heavy metals [4-6]. For polymers, this is a minor problem [7]. Therefore, at present, special attention is being paid to the development of new types of polymer composite materials for use in outer space [8-10].

Polymer composite materials, developed for the space industry, must withstand the loads of space flight, including high structural properties and resistance to high vacuum, radiation, micrometeorite particles, in particular, atomic oxygen, etc. [11-15]. In addition, the developed composites should have a wide operating temperature range from $-190{ }^{\circ} \mathrm{C}$ to $+200{ }^{\circ} \mathrm{C}[16]$.

One of the most promising is the use of polyimide as a binder for polymer composites for aerospace engineering. Polyimide has the highest thermal stability among polymers and has high physico-mechanical properties [17-21]. Pure polyimide has low radiation protective properties (linear attenuation coefficient of gamma rays $\mu=0.13 \mathrm{~cm}^{-1}$ at $\mathrm{E}=0.5 \mathrm{MeV}$ ), which does not allow its use in outer space. The impact of negative factors of space leads to a significant destruction of the polyimide in a radiation environment [22-27]. To prevent the destruction of polyimide in open space, it is reinforced with various fillers. The introduction of fillers can significantly improve the initial properties of polyimide, such as the operating temperature range, strength, radiation protection, etc. [28-31].

For example, silicon carbide $(\mathrm{SiC})$ nanoparticles are introduced into a polyimide matrix to enhance the thermal properties of the material [32]. To increase protection against neutron radiation, an introduction into polyimide of nanostructured boron carbide [33], $B_{4} C_{P}[34]$ is promising. However, the introduction of the proposed particles in polyimide, in large quantities, leads to a decrease in the mechanical properties of the composites [35,36]. To improve the physico-mechanical characteristics of polyimide composites, their reinforcement with carbon fiber is promising [37]. Aluminum oxide $\left(\mathrm{Al}_{2} \mathrm{O}_{3}\right)$ contributes to the thermo-oxidative protection of polyimide-based composites [38], and the silicone-containing material increases the resistance to UV-radiation [39]. To create polyimide composites, with high resistance to gamma radiation, it is necessary to use heavy inorganic particles, such as $\mathrm{PbO}, \mathrm{Bi}_{2} \mathrm{O}_{3}, \mathrm{Bi}_{12} \mathrm{SiO}_{20}[40,41]$.

One of the promising fillers for polymer composites for space applications are oxides of transition metals, in particular tungsten oxides, due to their high radiation resistance and high absorption coefficient of

\footnotetext{
* Corresponding author.

E-mail addresses: cherkashina.ni@bstu.ru, natalipv13@mail.ru (N.I. Cherkashina).
} 
$\mathrm{X}$-ray and gamma radiation (linear attenuation coefficient of gamma rays $\mu=1.62 \ldots 1.75 \mathrm{~cm}^{-1}$ at $\mathrm{E}=0.5 \mathrm{MeV}$ ) [42-44]. Depending on the oxygen content, tungsten oxides are dielectrics, semiconductors and superconductors $[45,46]$. $\mathrm{WO}_{2}$ is stable in vacuum up to $1800^{\circ} \mathrm{C}$ and up to $500{ }^{\circ} \mathrm{C}$ in the presence of oxygen, unlike $\mathrm{WO}_{3}$, which has 11 polymorphic transformations depending on the temperature and pressure [47]. Each phase has a specific set of physico-chemical characteristics. Therefore, the use of $\mathrm{WO}_{3}$ as a filler for a composite in space can lead to the destruction of the structure of the composite with a sharp temperature difference from $-190{ }^{\circ} \mathrm{C}$ to $+200{ }^{\circ} \mathrm{C}$. In contrast to tungsten hexavalent oxide, $\mathrm{WO}_{2}$ has a high density of $12.1 \mathrm{~g} / \mathrm{cm}^{3}$, is thermally stable, non-toxic, and has wide technological possibilities of production, which makes its use as a filler for a polymer composite for space applications quite topical.

One of the most important aspects of the use of highly filled composites in outer space is the stability of the physico-mechanical properties to a large temperature difference from $-190^{\circ} \mathrm{C}$ to $+200^{\circ} \mathrm{C}$. When a satellite moves in its orbit around the Earth, it experiences a high temperature difference. At first it is exposed to sunlight and the temperature rises to $+200^{\circ} \mathrm{C}$, and when it is in the shadow of the Earth, its temperature significantly decreases to $-190^{\circ} \mathrm{C}$, with this cycle being repeated many times [16]. Therefore, for the development of new polymer composites for cosmic purposes, it is important to study their physico-mechanical properties under thermal cycling conditions from $-190{ }^{\circ} \mathrm{C}$ to $+200{ }^{\circ} \mathrm{C}$

This paper presents the synthesis of polymer composites based on polyimide and modified $\mathrm{WO}_{2}$. The morphology of the highly filled composites was determined and their thermal and physico-mechanical characteristics were studied. The paper also presents research on the change of physico-mechanical characteristics in terms of thermal cycling from $-190{ }^{\circ} \mathrm{C}$ to $+200^{\circ} \mathrm{C}$.

\section{Experimental section}

\subsection{Synthesis}

For the synthesis of polymer composites, a polyimide pressing grade PI-PR-20 (JSC Institute of Plastics named after G.S. Petrov, Moscow, Russia) was used as a binder in the form of a fine powder. Technical characteristics of the used powder are presented in Table 1.

$\mathrm{WO}_{2}$ was used as a filler (manufactured by Plant of Rare Metals LLC, Novosibirsk). $\mathrm{WO}_{2}$ was in the form of a brown powder with a density of $12.1 \mathrm{~g} / \mathrm{cm}^{3}$.

To modify the surface of the $\mathrm{WO}_{2}$, a polyalkylsiloxane liquid with an active hydrogen content of $1.35 \%$ was used. The density of the liquid was $1 \mathrm{~g} / \mathrm{cm}^{3}$, the kinematic viscosity was $125 \mathrm{~mm}^{2} / \mathrm{s}$.

$\mathrm{WO}_{2}$ modification was carried out in a ball mill with the lowest possible load of grinding balls (no more than 15\%). Previously the polyalkylhydrosiloxane liquid was dissolved in xylene in the following ratio: $65 \mathrm{wt} \%$ polyalkylsiloxane fluid and $35 \mathrm{wt} \%$ xylene. After comilling $\mathrm{WO}_{2}$ and a solution of a polyalkylhydrosiloxane liquid in xylene, the mixture was dried at $150{ }^{\circ} \mathrm{C}$ for $90 \mathrm{~min}$, to carry out the polymerization and consolidation of the $\mathrm{C}_{2} \mathrm{H}_{5}$ - groups onto the $\mathrm{WO}_{2}$ particles [48], due to which, the $\mathrm{WO}_{2}$ modified by the proposed method became a hydrophobic substance.

Polymer composites of different modified $\mathrm{WO}_{2}$ weight $\%(0,10,30$,

Table 1

Technical characteristics of polyimide powder brand PI-PR-20.

\begin{tabular}{ll}
\hline Parameter & Value \\
\hline Dispersibility, $\mu \mathrm{m}$ & $100-500$ \\
Mass fraction of volatile, $\%$ & 0.5 \\
Charpy impact strength without cut, $\mathrm{kJ} / \mathrm{m}^{2}$ & 25 \\
Tensile stress at break at $20^{\circ} \mathrm{C}, \mathrm{MPa}$ & 92 \\
\hline
\end{tabular}

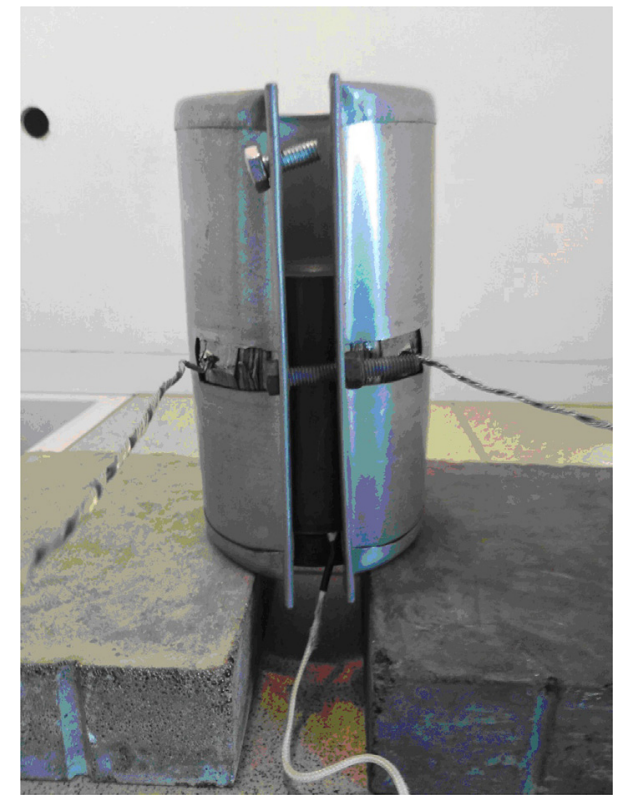

Fig. 1. Photograph of a mold design with a heating device.

60) were fabricated. Mixing of the powder components of the binder and the modified filler was carried out in a jet-vortex mill, brand VSM10 , for $30 \mathrm{~min}$. The use of a jet-vortex mill allows not only the mixing of the components, but also the production of a high-purity product with a large specific surface area [49-51]. The resulting powder mixture was loaded into a specialized cylindrical mold. The mold was heated by an electric heating element. The body of the heater was made of ceramic raw materials, which was encased in metal. Inside is a ceramic tube, around which was wound a spiral of nichrome origin. A photograph of the mold design with the heating device is shown in Fig. 1. A thermostat was connected to the mold and the heating was controlled to a temperature of $\sim 390^{\circ} \mathrm{C}$. When the temperature reached $390^{\circ} \mathrm{C}$, the mixture of components was heated for at least $1 \mathrm{~h}$, and then pressed at a pressure of $100 \mathrm{MPa}$. The materials obtained were composite disks with a diameter of $3 \mathrm{~cm}$.

\subsection{Characterization techniques}

X-ray phase analysis of the films was carried out in $\mathrm{Cu}-\mathrm{K} \alpha$ $(\lambda=0.154 \mathrm{~nm})$ by a sliding beam method: the fixed angle of the diffractometer tube was $\theta=5^{\circ}$ and the angle $2 \theta$ varied from $40^{\circ}$ to $90^{\circ}$. PDWin software (DrWin, Qual) used the PDF JCPDS database (version 2.02 1999).

A TESCAN MIRA 3 LMU auto-emission electron microscope (TESCAN, Czech Republic) was used for scanning electron microscopy. This allowed high resolution images, of the surface under study, to be obtained, especially at low accelerating voltages.

A thermal analyzer, STA 449 F1 Jupiter (NETZSCH), was used for simultaneous thermal analysis. The materials were investigated in the temperature range from 20 to $1000^{\circ} \mathrm{C}$. The heating rate was $5 \mathrm{~K} / \mathrm{min}$. Heating and recording of properties were carried out in a gas environment of oxygen $\left(\mathrm{O}_{2}\right)$ and argon (Ar). Tests of the images of composites in tension were carried out according to the method specified in DIN EN ISO 527. For this, samples of size $250 \times 25 \times 2.5 \mathrm{~mm}$ were cut using a water-jet before the samples were subjected to grinding using a polishing wheel BRUNI, for polymeric materials.

For heating the samples, a ShS-80-01 MK SPU drying cabinet was used, and liquid nitrogen, stored in a Dewar vessel, was used for the cryogenic treatment. The complete thermocycling procedure for all samples was as follows: 
(a)

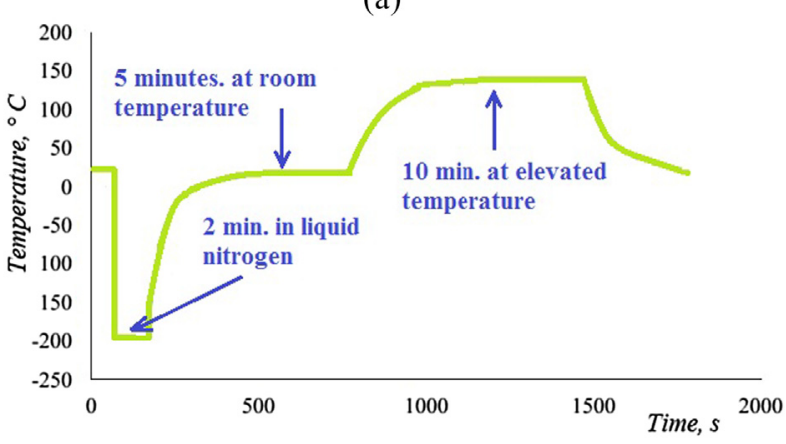

(b)

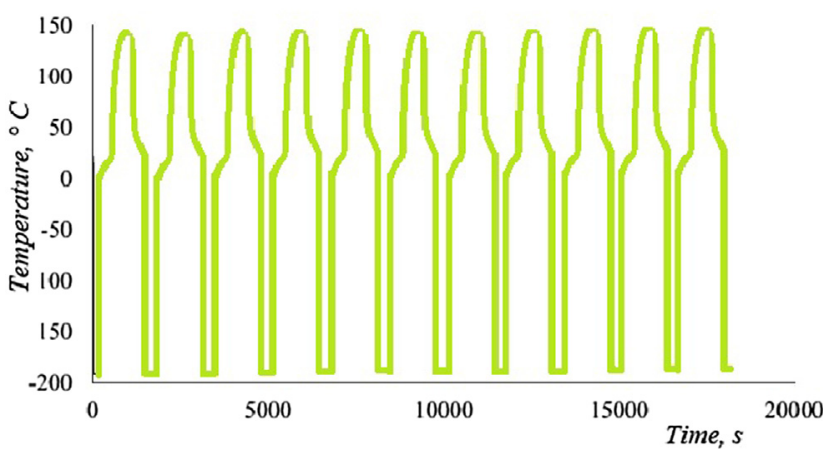

Fig. 2. Temperature cycle of material processing: (a) one full cycle and (b) ten cycles.

(1) Held in a cold environment $\left(-190^{\circ} \mathrm{C}\right)$ for $2 \mathrm{~min}$,

(2) Held at room temperature $\left(+23^{\circ} \mathrm{C}\right)$ for $5 \mathrm{~min}$,

(3) Held in a hot environment $\left(+200^{\circ} \mathrm{C}\right)$ for $10 \mathrm{~min}$,

(4) Held at room temperature $\left(+23^{\circ} \mathrm{C}\right)$ for $5 \mathrm{~min}$.

The time of one cycle was $22 \mathrm{~min}$. The thermal cycle was repeated 5 , 10 and 20 times. Fig. 2 shows a schematic of the temperature cycle of the materials processing.

After the required number of thermal cycles, samples of the polymer composites were subjected to a tensile test using the universal tensile testing machine EUS-40 (with a pulsator) $20 \mathrm{kN}$. The following parameters were determined: tensile strength, modulus of tensile elasticity and elongation under tension. The tensile strength of polymer composites before and after thermal cycling was determined according to Eq. (1):

$\sigma_{p}=\frac{F_{p}}{S_{0}}$

where $F_{p}$ is the load at which the polymer composite has been destroyed, N; $S_{0}=b \times h$ is the initial cross section of a sample of the polymer composite material, $\mathrm{mm}^{2} ; b, h$ is the width and thickness of the sample of the polymer composite material, respectively $\mathrm{mm}$.

The elongation of the sample polymer composite material at the time of destruction, $\Delta l$ determined the relative elongation at break by Eq. (2):

$\varepsilon=\frac{\Delta l}{l_{0}} \cdot 100 \%$

where $\Delta l$ is the change in the estimated length of the sample polymer composite material at the time of rupture $\mathrm{mm}$; $l_{0}$ is the calculated length $\mathrm{mm}$.

The modulus of elasticity was determined by Eq. (3):

$E_{p}=\frac{\left(F_{2}-F_{1}\right) \cdot l_{0}}{S_{0} \cdot\left(\Delta l_{2}-\Delta l_{1}\right)}$

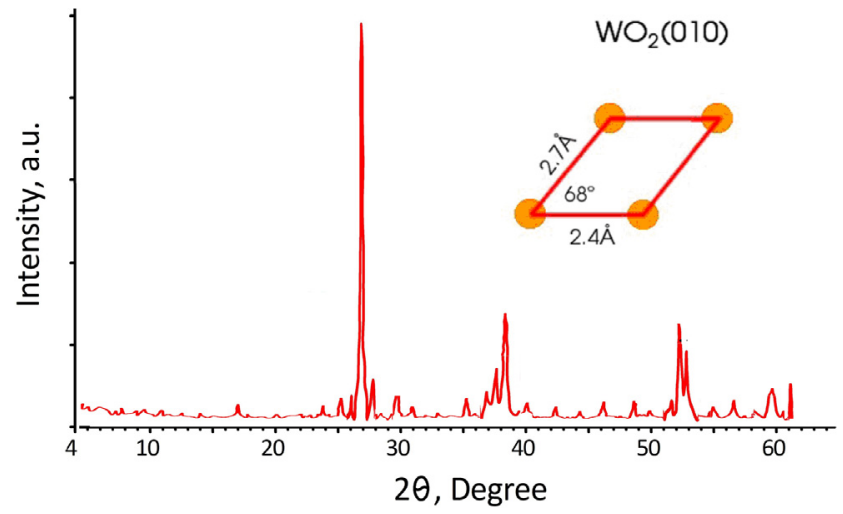

Fig. 3. X-ray powder diffractogram of source filler.

where $F_{1}, F_{2}$ are the values of the loads corresponding to the relative elongation of the sample of the polymer composite material $0.1 \%$ and $0.3 \%, \mathrm{~N} ; \Delta l_{1}, \Delta l_{2}$ are the elongation at loads $F_{1}, F_{2}$, respectively mm.

\section{Results and discussion}

\subsection{Surface morphology of the obtained composites}

The X-ray powder diffractogram of the filler is shown in Fig. 3. It has been established that the initial sample of the filler is a single-phase crystalline product $\mathrm{WO}_{2}$, corresponding to card No. 71-614 in the PDF2 powder diffractogram database. $\mathrm{WO}_{2}$ crystals have a monoclinic structure with the following lattice parameters: $a=5.563, b=4.896$, $c=5.563$. The diffraction maximum is observed at $d=3.42 \AA$. In the $\mathrm{WO}_{2}$ crystal in the $(010)$ plane, the distance between the molecules along one of the lattice translation vectors is $2.7 \AA$. In the other direction, it is $2.4 \AA$. The angle between the vectors is $68^{\circ}$ [52].

The morphology of the original $\mathrm{WO}_{2}$ particles was examined using scanning electron microscopy. Fig. 4 shows the SEM images of $\mathrm{WO}_{2}$ particles at different resolutions. According to the electron microscopy data, the $\mathrm{WO}_{2}$ particles are crystals, mostly cubic in shape, with sizes of 150-200 nm (Fig. 4b). It can be seen that the $\mathrm{WO}_{2}$ nanoparticles are subject to strong aggregation with the size of the aggregated particles reaching $30 \mu \mathrm{m}$ (Fig. 4a).

The introduction of aggregated particles into the polymer matrix will lead to a non-uniform distribution of the filler. This will have a negative impact on the thermal and physical-mechanical properties of the final composite. There are various ways to evenly distribute fine particles and incorporate them into the composite structure. The main ones are: mechanical dispersion, sonication, magnetodynamic treatment, chemical surface activation, electrodeposition, and so on [53-55]. These are often used as combined methods. In this work, the method of chemical activation of the surface of $\mathrm{WO}_{2}$ by modifying a polyalkylhydrosiloxane liquid, was used.

Fig. 5 shows the SEM images of the obtained composites using modified (Fig. 5b, d) and unmodified (Fig. 5a and c) $\mathrm{WO}_{2}$ with the same content of filler ( $60 \mathrm{wt} \%)$.

As can be seen from the micrographs of the surface of all composites, polyimide particles (dark region) bind $\mathrm{WO}_{2}$ particles (light region) to form a single composite. No chips or cracks were found on the surface of all the samples studied. This indicates a strong physicochemical interaction of the components in the polymer-filler system. As can be seen from Fig. $5 \mathrm{~b}$, the use of modification leads to a uniform distribution of $\mathrm{WO}_{2}$ in the entire volume of the composite. In some areas there is a small number of agglomerates, of various shapes, not exceeding $2 \mu \mathrm{m}$ in size. The use of unmodified filler (Fig. $5 \mathrm{a}$ and c) leads to a significant increase in the size of the agglomerates. The aggregated $\mathrm{WO}_{2}$ particles reach $20 \mu \mathrm{m}$. Thus, the use of $\mathrm{WO}_{2}$ modification, when introduced into a polyimide matrix, prevents particles from aggregating 
(a)

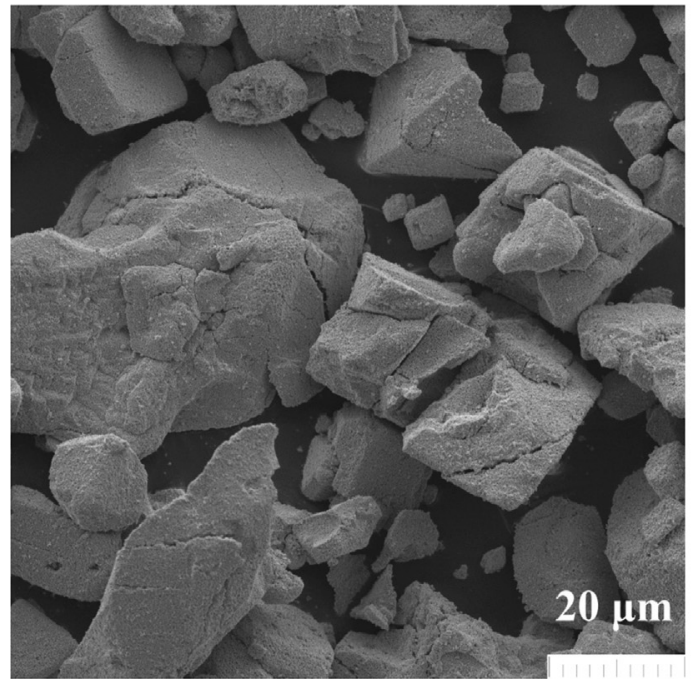

(b)

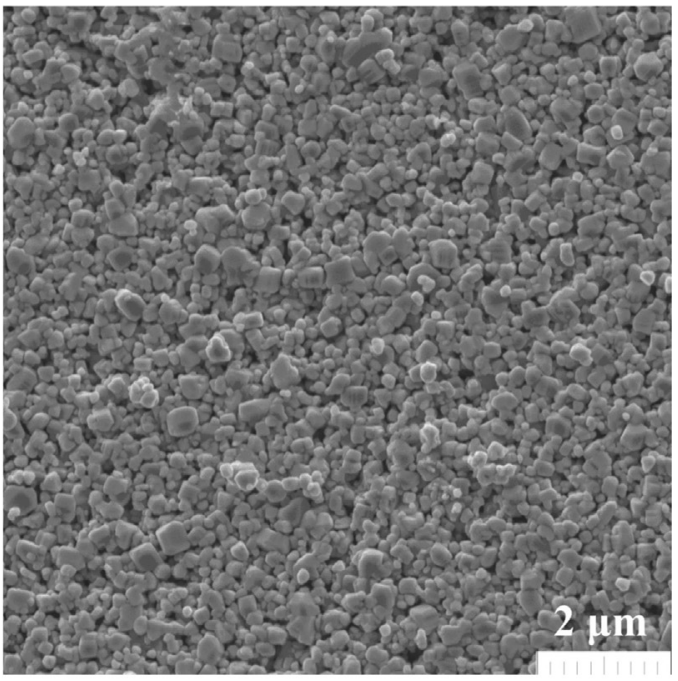

Fig. 4. SEM images of $\mathrm{WO}_{2}$ particles at different resolutions.

(a)

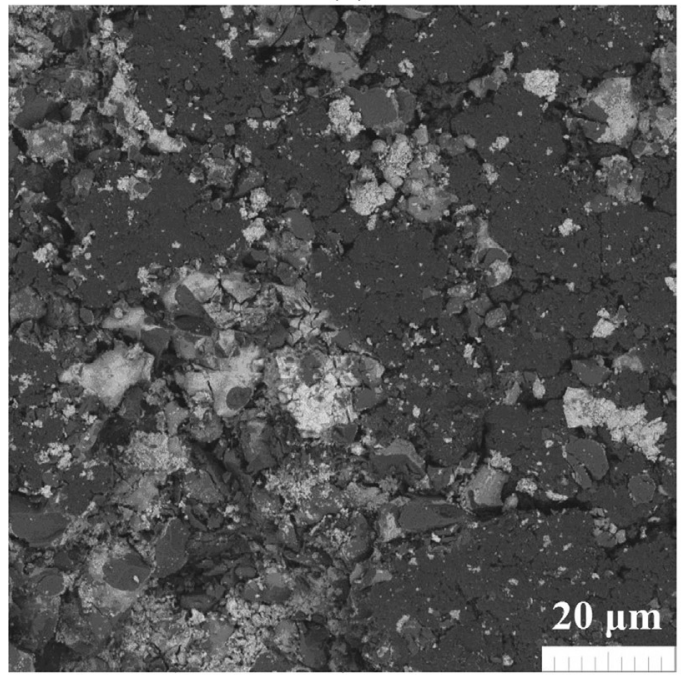

(c)

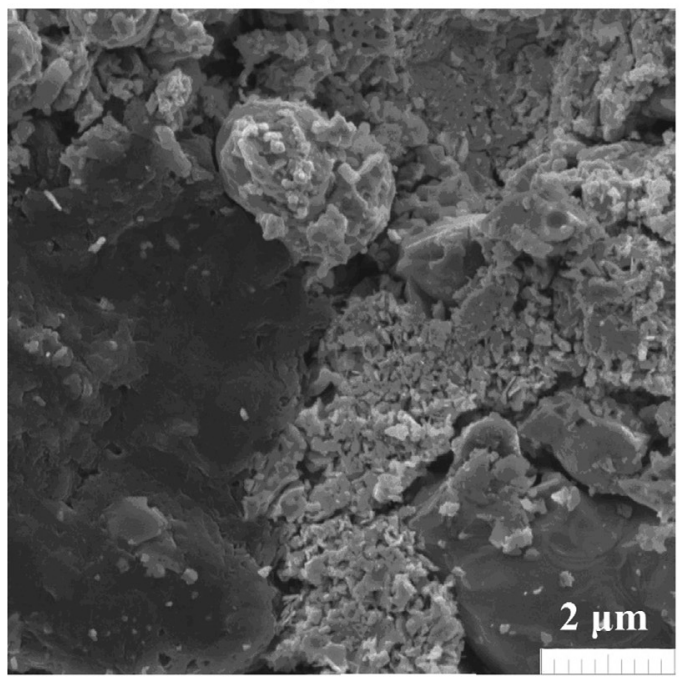

(b)

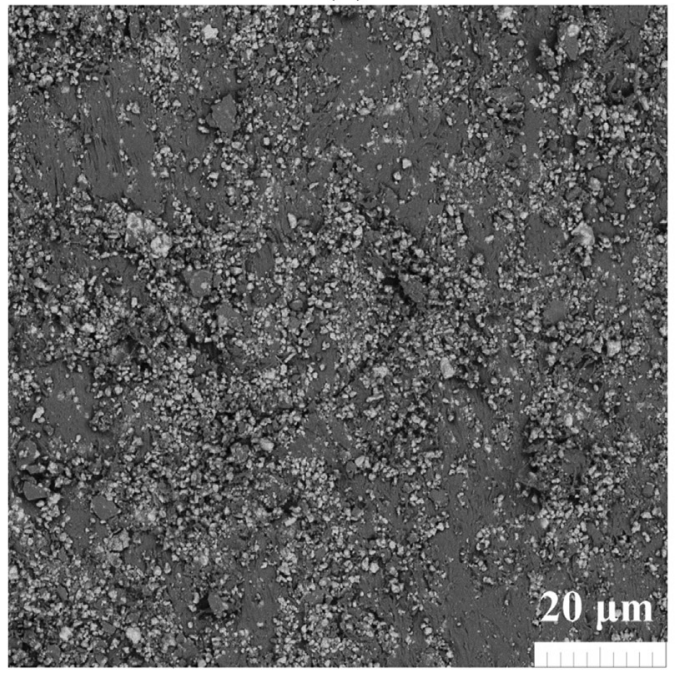

(d)

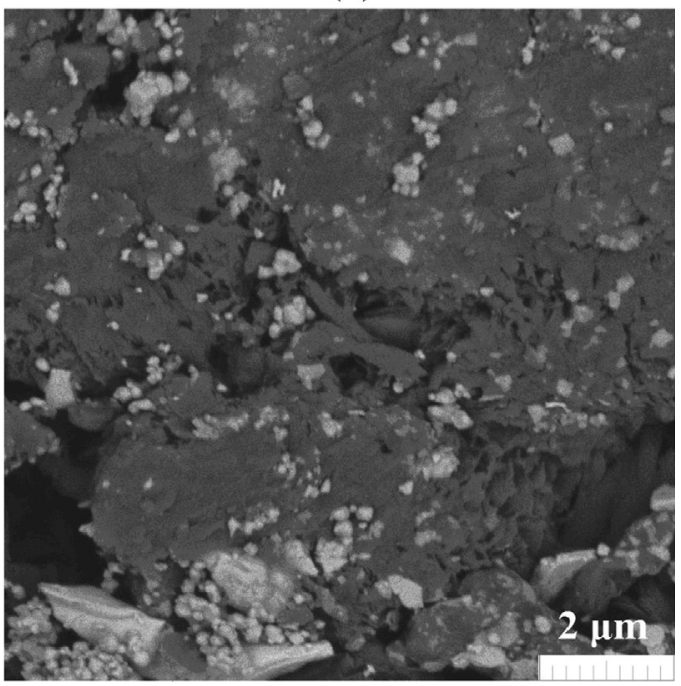

Fig. 5. SEM images of a polyimide composite with $60 \mathrm{wt} \% \mathrm{WO}_{2}$ with: (a, c) - unmodified filler; (b, d) - modified filler. 
(a)

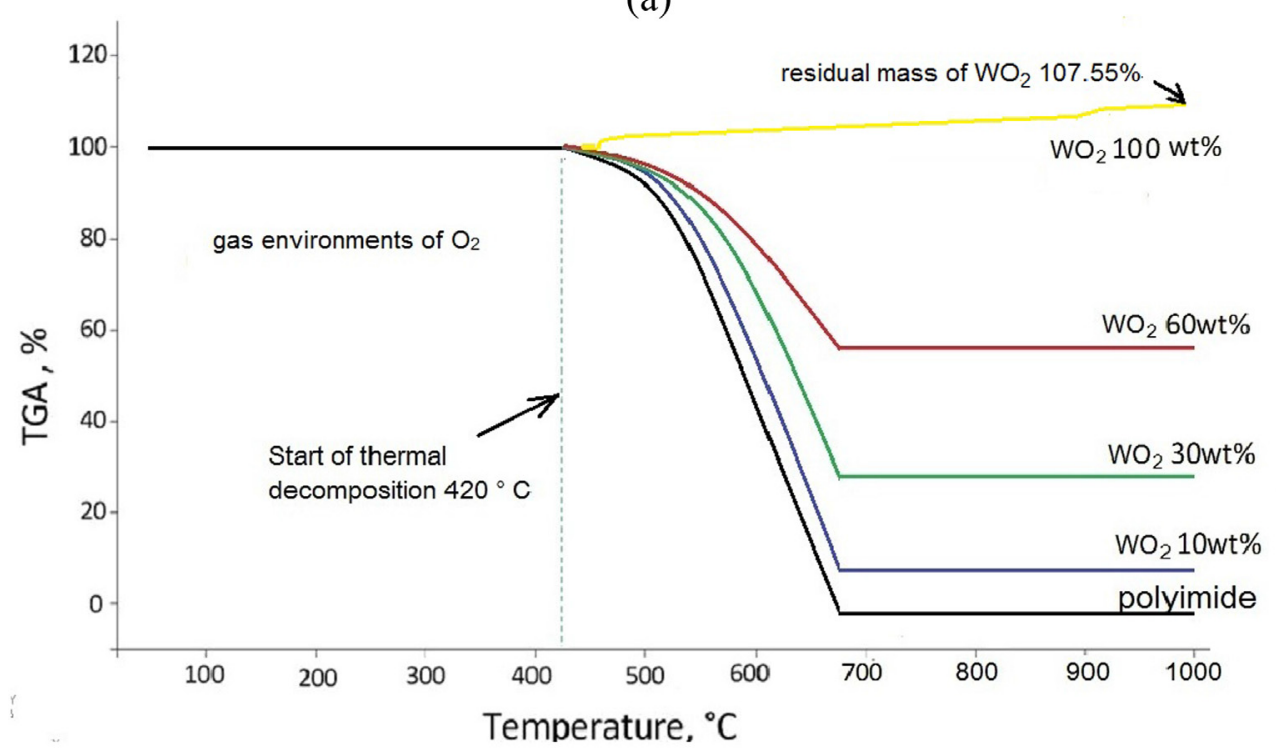

(b)

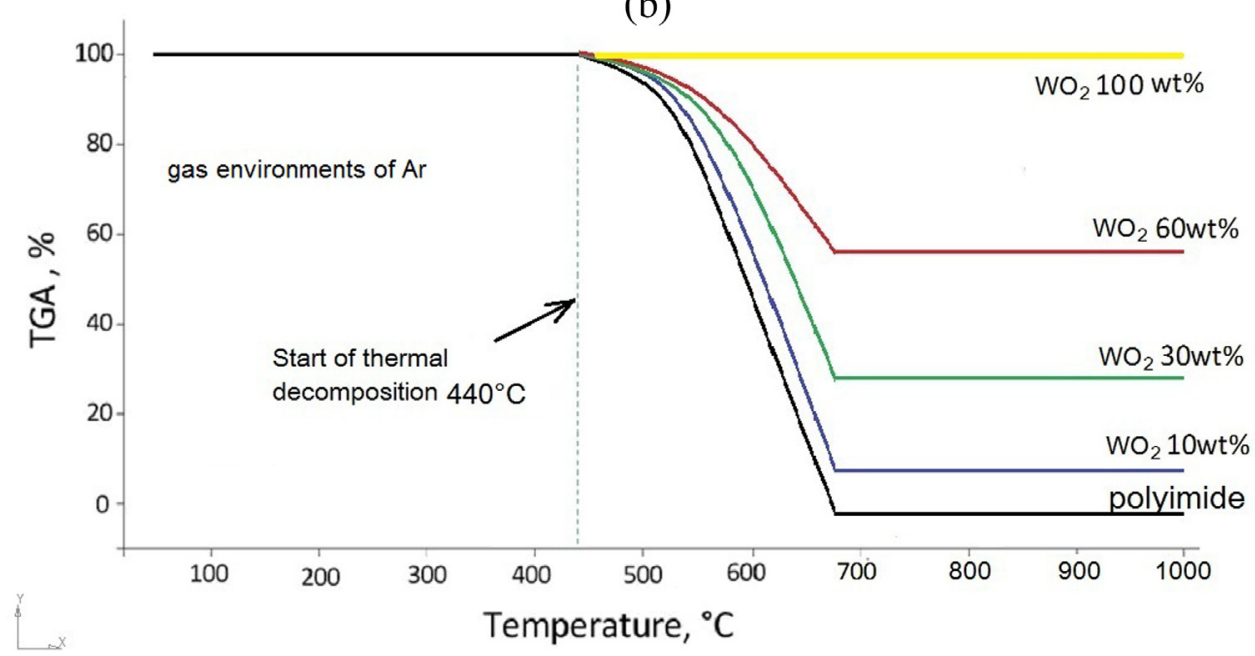

Fig. 6. TGA curves for composites in the gas environment of $\mathrm{O}_{2}$ (a) and in the gas environment of Ar (b).

and allows them to be evenly distributed throughout the entire polymer volume.

\subsection{Thermal analysis of the obtained composites}

One of the main characteristics of polymers and their composites is thermal stability (the upper limit of the operating temperature). In this work, in order to estimate the upper limit of the working temperature and assess the physical transitions in the structure of composites accompanied by thermal effects, a thermal analysis of composites, with different contents of modified $\mathrm{WO}_{2}$, was carried out. The following methods of thermal analysis were used: thermogravimetric analysis (TGA) and differential thermal analysis (DTA). Studies were carried out at a temperature of from 20 to $1000{ }^{\circ} \mathrm{C}$ in a gas environment of oxygen $\left(\mathrm{O}_{2}\right)$ and argon (Ar). The standard was the $\mathrm{Al}_{2} \mathrm{O}_{3}$ charge. Fig. 6 shows the obtained TGA curves of pure polyimide, filler, and composites in a gas environment of $\mathrm{O}_{2}$ (Fig. 6a) and in a gas environment of $\mathrm{Ar}$ (Fig. 6b). The maximum content of modified $\mathrm{WO}_{2}$ in the studied composites was $60 \mathrm{wt} \%$. With a higher content of filler, there was a lack of binder for the formation of components into a single composite.

Fig. 6a shows that in a gas environment of $\mathrm{O}_{2}$, pure polyimide is thermostable to a temperature of $420^{\circ} \mathrm{C}$ without any loss of mass showing on the TGA curve. In the gas environment of Ar, the thermal stability of the polyimide increases slightly to $440{ }^{\circ} \mathrm{C}$ (Fig. 6b). The temperature of the end of thermal decomposition of the polymer, in both gas environments is $680^{\circ} \mathrm{C}$. Fig. $6 \mathrm{a}$ shows that in a gas environment of $\mathrm{O}_{2}, \mathrm{WO}_{2}$ is thermostable to a temperature of $472{ }^{\circ} \mathrm{C}$ without any changes showing on the TGA curve. Above $472{ }^{\circ} \mathrm{C}$, an increase in $\mathrm{WO}_{2}$ mass on the TGA curve is observed (Fig. 6a). At a temperature of $1000{ }^{\circ} \mathrm{C}$, the residual mass of $\mathrm{WO}_{2}$ is $107.55 \%$. Fig. $6 \mathrm{~b}$ shows that in a gas environment of $\mathrm{Ar}$, the proposed $\mathrm{WO}_{2}$ filler is thermostable over the entire temperature range of the study. No weight loss was recorded up to $1000{ }^{\circ} \mathrm{C}$ on the TGA $\mathrm{WO}_{2}$ curve (Fig. 6b).

Analysis of the curves in Fig. 6 shows that a sample of polyimide has the greatest mass loss compared with composites filled with $\mathrm{WO}_{2}$, both in a gas environments of $\mathrm{O}_{2}$ and Ar. Since the upper limit of the operating temperature for polymers is determined by the temperature at which there is a loss of no more than $5 \%$ of the mass, for pure polyimide the limit of the operating temperature is $507^{\circ} \mathrm{C}$, for a composite with a content of: $10 \mathrm{wt} \% \mathrm{WO}_{2}-511{ }^{\circ} \mathrm{C}, 30 \mathrm{wt} \% \mathrm{WO}_{2}-526^{\circ} \mathrm{C}$ and $60 \mathrm{wt} \%$ $\mathrm{WO}_{2}-554^{\circ} \mathrm{C}$ in a gas environment of Ar Therefore, the introduction of a more thermostable filler, compared to polyimide, made it possible to create composites with an increased temperature range of operation.

Fig. 7 shows the DTA curves of pure polyimide, a filler, and composites in a gas environment of $\mathrm{O}_{2}$ (Fig. 7a) and in a gas environment of Ar (Fig. 7b). It can be noted that the DTA curves of pure polyimide in 
(a)

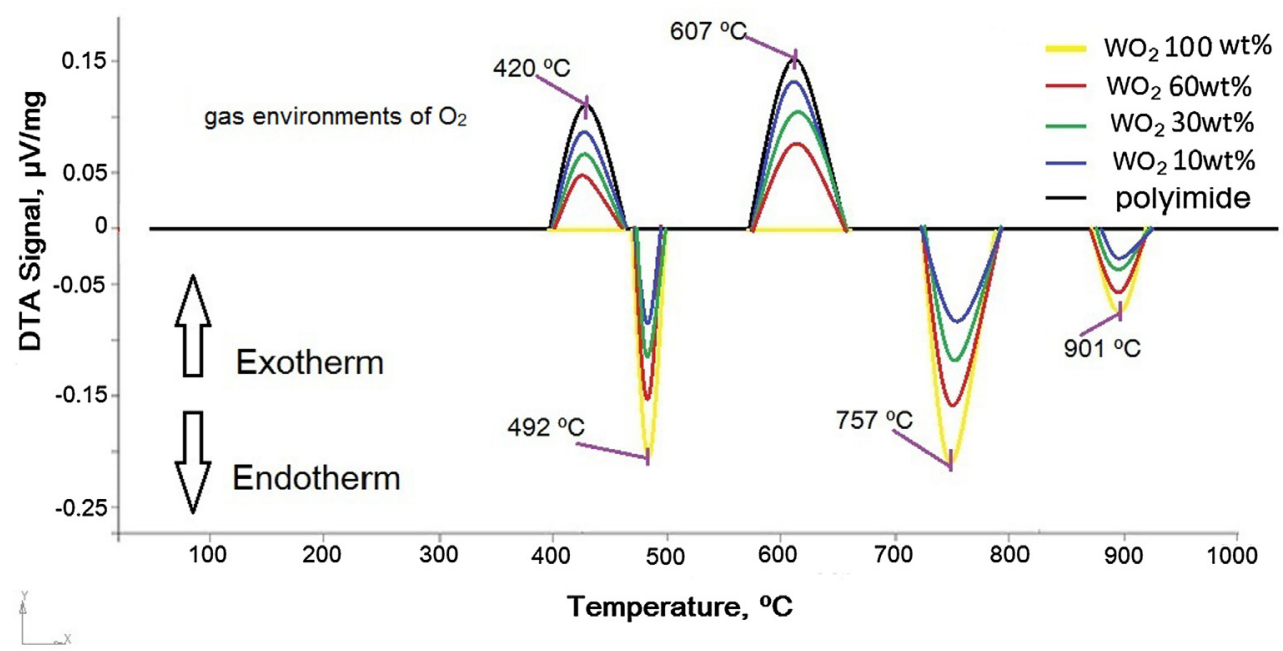

(b)

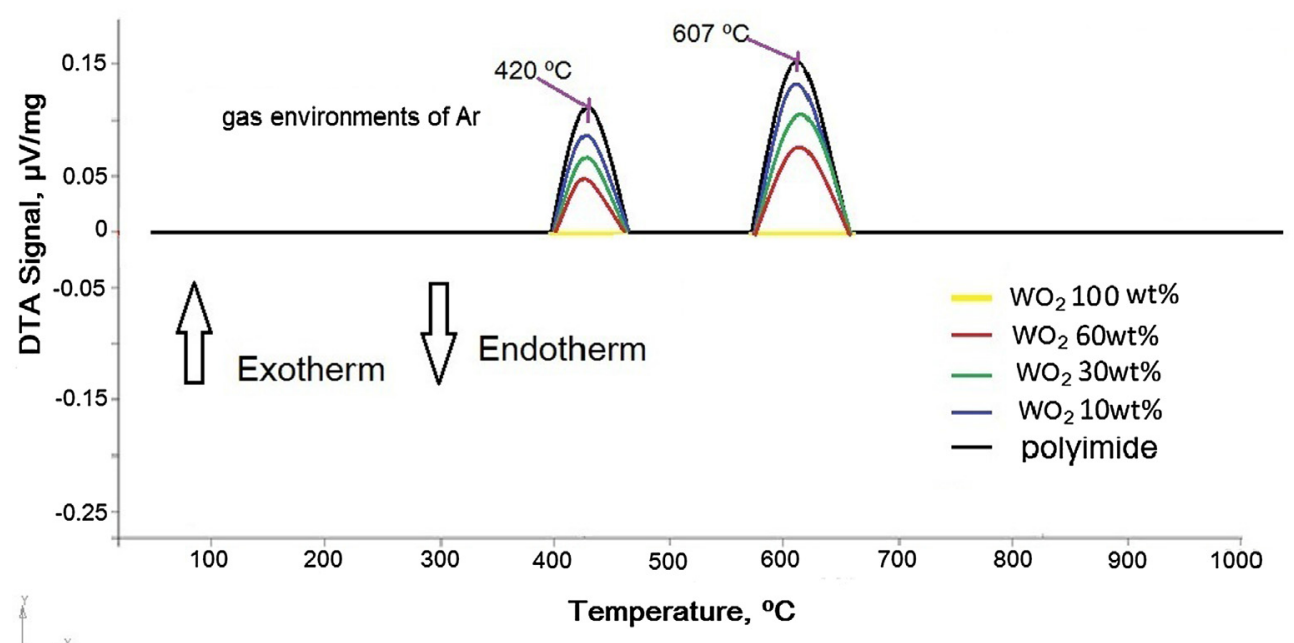

Fig. 7. DTA curves for composites in the gas environment of $\mathrm{O}_{2}$ (a) and in the gas environment of Ar (b).

the gas environment of $\mathrm{O}_{2}$ and in the gas environment of $\mathrm{Ar}$, are almost the same.

DTA curves of pure polyimide are characterized by a long exothermic effect with a pronounced maximum at $607^{\circ} \mathrm{C}$. The peak at this temperature corresponds to the maximum rate of decomposition of the polymer. The second, less intense, peak at $420^{\circ} \mathrm{C}$ in the gas environment of $\mathrm{O}_{2}$ (Fig. $7 \mathrm{a}$ ) and at $440{ }^{\circ} \mathrm{C}$ in the gas environment of Ar (Fig. 7b) corresponds to the onset of thermal degradation of the polymer. At this temperature, the TGA curve begins to decline, which indicates the beginning of mass loss.

In contrast to the DTA polyimide curves, the DTA curves of $\mathrm{WO}_{2}$, in the gas environment of $\mathrm{O}_{2}$ (Fig. 7a) and in the gas environment of $\mathrm{Ar}$ (Fig. 7b), differ greatly. No exothermic or endothermic effects were recorded on the DTA curve of $\mathrm{WO}_{2}$ in the gas environment of Ar. With the DTA curve of $\mathrm{WO}_{2}$ in, the gas environment of $\mathrm{O}_{2}$ there are three distinct peaks. The first extended endothermic effect, with a pronounced maximum at $492{ }^{\circ} \mathrm{C}$, is obviously associated with the reaction of $\mathrm{WO}_{2}$ with $\mathrm{O}_{2}$ at high temperature, with the result that hexavalent tungsten oxide, $\mathrm{WO}_{3}$ is formed. The second pronounced endothermic effect on the DTA curve of $\mathrm{WO}_{2}$, at a temperature of $757^{\circ} \mathrm{C}$ seems to be related to the recrystallization of the resulting $\mathrm{WO}_{3}$ from the monoclinic (I) or c-phase P21/n (C52) in orthorhombic Pmnb (D162) crystalline phase [47]. The third, least pronounced, peak in the DTA curve of $\mathrm{WO}_{2}$ at a temperature of $901^{\circ} \mathrm{C}$, is also associated with the recrystallization of the resulting $\mathrm{WO}_{3}$ from the orthorhombic Pmnb (D162) in tetragonal P4/nmm (D74) crystalline phase [47]. On the DTA curves of the composites there are peaks corresponding to both polyimide and filler. New exo-or endothermic effects on the DTA curves of the composites were not detected.

\subsection{Physico-mechanical properties of the obtained composites under} thermal cycling conditions from $-190^{\circ} \mathrm{C}$ to $+200^{\circ} \mathrm{C}$

One of the most important environmental effects of materials based on polymers used in space, is the thermal cycle, in which the composite undergoes a large temperature difference from $-190^{\circ} \mathrm{C}$ to $+200^{\circ} \mathrm{C}$. When a satellite moves in its orbit around the Earth, it experiences a high temperature difference: at first it is exposed to sunlight and the temperature increases $\left(+200^{\circ} \mathrm{C}\right)$, and when it is in the shadow of the Earth its temperature significantly decreases to $-190^{\circ} \mathrm{C}$. This cycle is repeated many times. Continuous thermal cycles, in outer space, can cause the formation of microcracks in materials, a deterioration of the physico-mechanical characteristics, which will lead to the complete destruction of the material. The developed composites were subjected to thermal cycling tests in the temperature range from $-190^{\circ} \mathrm{C}$ to $+200^{\circ} \mathrm{C}$. 


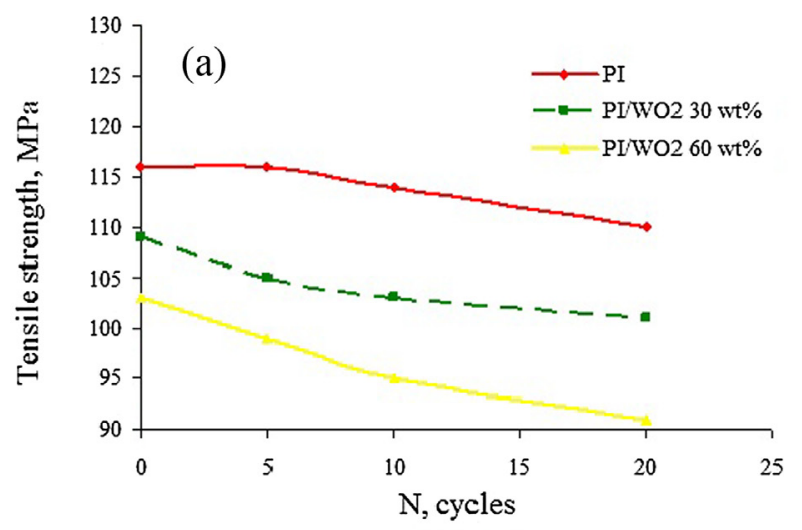

(b)

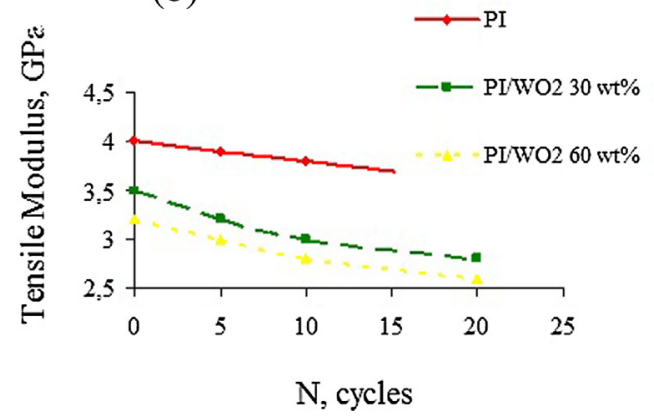

(c)

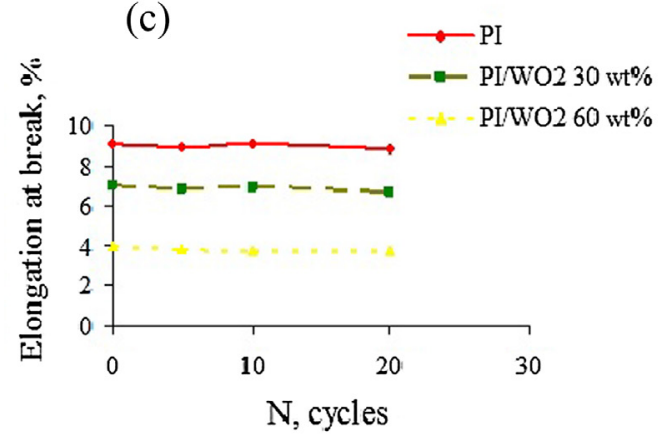

Fig. 8. Curves of tensile strength (a), modulus of tensile elasticity (b) and elongation at break (c) versus the number of temperature holding cycles.

Fig. 8 shows graphs of the tensile strength (Fig. 8a), the modulus of tensile elasticity (Fig. 8b), and the elongation at break (Fig. 8c) of the materials under investigation versus the number of temperature exposure cycles.

Analysis of the data in Fig. 8 shows that the initial sample of polyimide has the largest tensile strength and modulus of tensile elasticity compared to highly filled composites. However, after thermal cycling, there is a slight decrease in these parameters. After 10 cycles a decrease in the tensile strength of the polyimide sample by $1.7 \%$ is observed, and after 20 cycles, a decrease of $5.2 \%$ (Fig. 8a). A similar situation is observed with the values of the modulus of tensile elasticity, after 10 cycles a decrease of $5 \%$ is observed, and after 20 cycles a decrease of $10 \%$ is observed (Fig. 8 b).

The introduction of a modified $\mathrm{WO}_{2}$ filler reduces the initial strength characteristics of composites. After thermocycling, as in the case for pure polyimide, a slight decrease in tensile strength and tensile modulus is observed. For a highly-filled composite sample, with a $60 \%$ content of modified $\mathrm{WO}_{2}$, after 10 cycles, a tensile strength of the composite decreases by $3.9 \%$, and after 20 cycles by $11.6 \%$ (Fig. $8 \mathrm{a}$ ). The modulus of tensile elasticity, of a highly filled composite after 10 cycles, decreases from $3.5 \mathrm{GPa}$ to $3 \mathrm{GPa}$, and after 20 cycles its value is minimum and equal to $2.8 \mathrm{GPa}$ (Fig. $8 \mathrm{~b}$ ).

An analysis of the elongation values at break (Fig. 8c) showed that the purest polyimide samples had the greatest elongation at the time of destruction. The arithmetic mean value of the elongation at break for samples of pure polyimide without filler, subjected to different number of thermal cycles is $8.9 \%$. For a sample with $30 \mathrm{wt} \%$ content of modified $\mathrm{WO}_{2}$, this value is $6.8 \%$, and for the composite with the highest content of $60 \mathrm{wt} \%$ modified $\mathrm{WO}_{2}-3.8 \%$.

As can be seen from Fig. 8, the thermal cycling of all the materials under study, as expected, led to a decrease in such mechanical characteristics as tensile strength and modulus of tensile elasticity. However, in the case of highly filled $\mathrm{WO}_{2}$-modified composites, the decrease in mechanical characteristics turned out to be more significant compared to the sample of pure polyimide. This is explained by the fact that the matrix is less susceptible to a sharp temperature drop (from $-190{ }^{\circ} \mathrm{C}$ to $+200{ }^{\circ} \mathrm{C}$ ) compared with the composite materials, which is reflected in a significant deterioration in the mechanical characteristics of the composites compared to the polyimide (Fig. 8a, b).

Fig. 9 shows the SEM images of the composites after exposure to temperature cycles.

As can be seen from the micrographs of the surface of polyimide after exposure to temperature cycles (Fig. 9a and b), no chips or cracks were found on the surface of all the samples studied. There are microcracks on SEM image of the composite with $60 \mathrm{wt} \% \mathrm{WO}_{2}$ after exposure to 20 temperature cycles (Fig. 9d). Therefore, we can conclude that changes in the physico-mechanical characteristics of the composites filled with modified $\mathrm{WO}_{2}$, after thermocycling, are due to the occurrence of internal stresses in the composites due to the expansion and contraction of both the polyimide matrix and the particles of modified $\mathrm{WO}_{2}$, in accordance with their linear coefficients of thermal expansion [56]. Due to the large difference between the linear thermal expansion coefficient of polyimide $5 \cdot 10^{-5} \mathrm{~K}^{-1}$ (ASTM D 696) and the linear thermal expansion coefficient $\mathrm{WO}_{2}-2 \cdot 10^{-6} \cdot \mathrm{K}^{-1}$ a temperature change from $-190^{\circ} \mathrm{C}$ to $+200^{\circ} \mathrm{C}$ leads to changes in the thermal stress level in the composite. Since the components are internally limited, temperature fluctuations cause stress to build up at the interface [57]. One of the most serious problems during thermal cycling of composites is the breaking of bonds between their components, in this case the polyimide matrix and the modified $\mathrm{WO}_{2}$. Such a breakage is caused either by the expansion of pre-existing microcracks or the creation of new microcracks on the surface of the composite (Fig. 9d).

\section{Conclusions}

It has been shown that the use of a polyalkylhydrosiloxane liquid for modifying $\mathrm{WO}_{2}$, when introduced into a polyimide matrix, prevents aggregation of filler particles and allows them to be evenly distributed throughout the entire polymer volume. The use of unmodified filler leads to a significant increase in the size of the agglomerates. The 
(a)

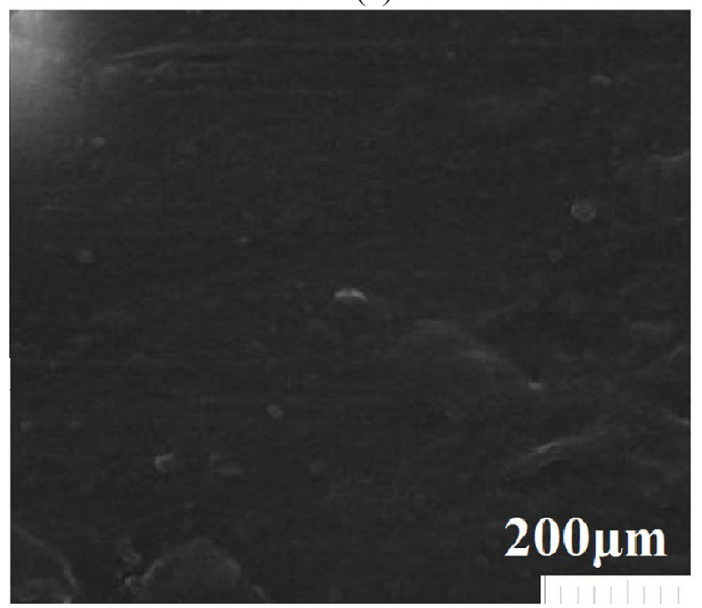

(c)

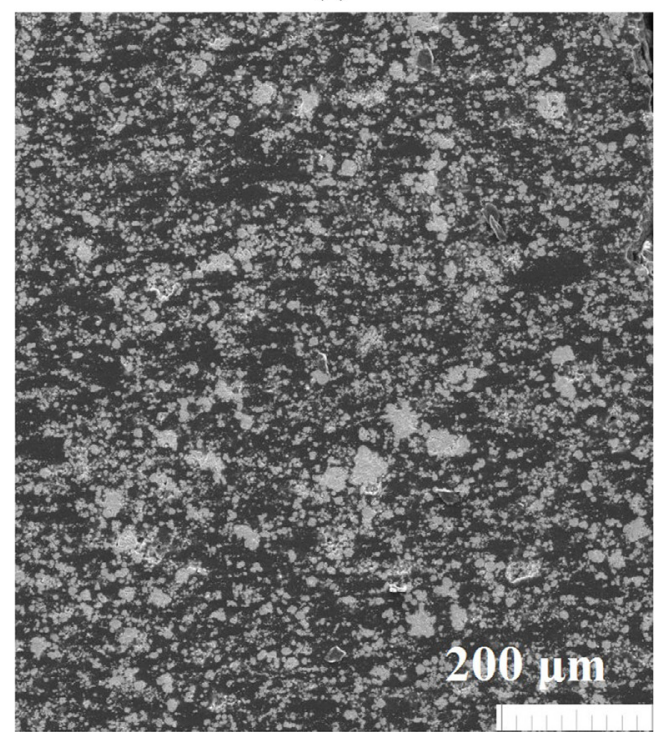

(b)

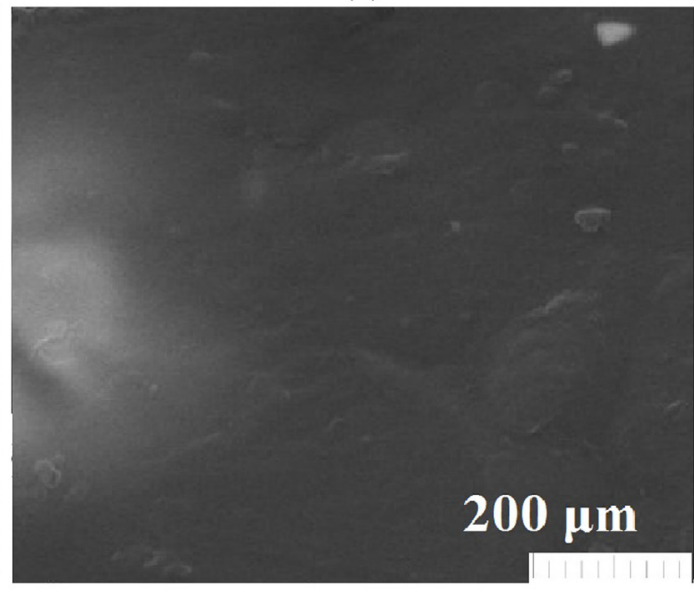

(d)

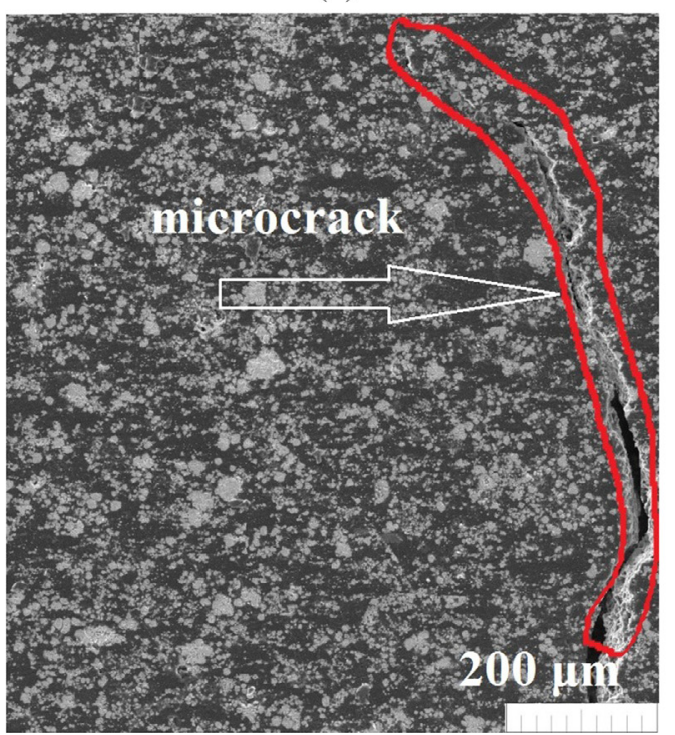

Fig. 9. SEM images of a polyimide (a,b) and polyimide composite with $60 \mathrm{wt} \% \mathrm{WO}_{2}$ (c,d) after exposure to 10 (a,c) and 20 (b,d) temperature cycles.

aggregated $\mathrm{WO}_{2}$ particles, in the transverse direction, reach $20 \mu \mathrm{m}$.

The polyimide sample has the highest mass loss compared with the $\mathrm{WO}_{2}$-filled composites both in the gas environment of $\mathrm{O}_{2}$ and in the gas environment of Ar. For pure polyimide, the upper limit of the working temperature is $507^{\circ} \mathrm{C}$; for a composite with a content of $10 \mathrm{wt} \% \mathrm{WO}_{2}-$ $511^{\circ} \mathrm{C}, 30 \mathrm{wt} \% \mathrm{WO}_{2}-526^{\circ} \mathrm{C}$ and $60 \mathrm{wt} \% \mathrm{wO}_{2}-554^{\circ} \mathrm{C}$ in a gas environment of Ar.

For a highly filled composite sample with a $60 \%$ modified $\mathrm{WO}_{2}$ content, after 10 cycles, the tensile strength of the composite decreases by $3.9 \%$, and after 20 cycles, decreases by $11.6 \%$. The modulus of tensile elasticity of a highly filled composite, after 10 cycles, decreases from $3.5 \mathrm{GPa}$ to $3 \mathrm{GPa}$, and after 20 cycles its value is minimum and equal to $2.8 \mathrm{GPa}$.

The developed composites can find application as radiation protective shields of electronic equipment located on the outer side of the spacecraft. Such radiation protective shields are not a supporting structure. Therefore, the obtained values of tensile strength, modulus of tensile elasticity and elongation at break after exposure to temperature cycles are sufficient.

\section{Funding}

The work was supported by a project of the Russian Science
Foundation (№ 19-19-00316).

\section{Declaration of Competing Interest}

The authors declare that they have no known competing financial interests or personal relationships that could have appeared to influence the work reported in this paper.

\section{Appendix A. Supplementary material}

Supplementary data to this article can be found online at https:// doi.org/10.1016/j.cryogenics.2019.102995.

\section{References}

[1] Inagaki I, Takechi T, Shirai Y, Ariyasu N. Application and features of titanium for the aerospace industry. Nippon Steel and Sumitomo Metal Technical Report. 2014;106: 22-7.

[2] Li Q, Xue S, Wang J, Shao S, Kwong AH, Giwa A, et al. High-strength nanotwinned $\mathrm{Al}$ alloys with 9R phase. Adv Mater 2018;30:1704629. https://doi.org/10.1002/ adma.201704629.

[3] Jöyset J. Scandium in aluminium alloys overview: physical metallurgy. Properties and applications. Metall Sci Technol 2007;25:11-7.

[4] Nikiforov AY, Chumakov AI, Simulation of space radiation effects in microelectronic parts, effects of space weather on technology infrastructure. NATO Science Series II: 
Mathematics, Physics and Chemistry, Springer, Dordrecht, v. 176; 2004

[5] Baker DN, Erickson PJ, Fennell JF, Foster JC, Jaynes AN, Verronen PT. Space weather effects in the Earth's radiation belts. Space Sci Rev 2018;214:17. https:// doi.org/10.1007/s11214-017-0452-7.

[6] Salvat F, Fernández-Varea JM, Sempau J, Llovet X. Monte Carlo simulation of bremsstrahlung emission by electrons. Radiat Phys Chem 2006;80:1201-9. https:// doi.org/10.1016/j.radphyschem.2005.05.008.

[7] Taylor EW, Pirich R, Weir J, Leyble D, Chu S, Taylor LR et al. Space radiation resistant hybrid and polymer materials for solar cells. In: 35th IEEE Photovoltaic Specialists Conference, Honolulu: HI; 2010.

[8] Balagna C, Perero S, Ferraris S, Miola M, Fucale G, Manfredotti C, et al. Antibacterial coating on polymer for space application. Mater Chem Phys. 2012;135:714-22. https://doi.org/10.1016/j.matchemphys.2012.05.049.

[9] Yadav R,Tirumali M, Wang X, Naebe M, Kandasubramanian B, Polymer composite for antistatic application in aerospace, Defence Technology, Available online 16 April 2019. https://doi.org/10.1016/j.dt.2019.04.008.

[10] Rana S, Fangueiro R, Advanced composite materials for aerospace engineering: processing, properties and applications. Woodhead Publishing Series in Composites Science and Engineering: Number 70, Amsterdam: Woodhead Publishing; 2016.

[11] Ortner HM, Stadermann FJ. Degradation of space exposed surfaces by hypervelocity dust bombardment, and refractory materials for space. Int J Refract Metals Hard Mater. 2009;27:949-56. https://doi.org/10.1016/j.ijrmhm.2009.05.009.

[12] Zhang J, Ai L, Li X, Zhang X, Lu Y, Chen G, et al. Hollow silica nanosphere/polyimide composite films for enhanced transparency and atomic oxygen resistance. Mater Chem Phys. 2019;222:384-90. https://doi.org/10.1016/j.matchemphys. 2018.10.022.

[13] Choi C, Kim YH, Kumar SKS, Kim C-G. Enhanced resistance to atomic oxygen of OG POSS/epoxy nanocomposites. Compos Struct. 2018;202:959-66. https://doi.org/ 10.1016/j.compstruct.2018.05.011.

[14] Liu Y, Yang X, Li M, Zhang Y, Zhao C, Qin W. Erosion effects of atomic oxygen on carbon nanotube arrays in different incidence direction. Surf Interface Anal 2018;50:592-8. https://doi.org/10.1002/sia.6416.

[15] Hossain UH, Ensinger W. Experimental simulation of radiation damage of polymers in space applications by cosmic-ray-type high energy heavy ions and the resulting changes in optical properties. Nucl Instrum Meth B 2015;365:230-4. https://doi. org/10.1016/j.nimb.2015.06.007.

[16] Yang B, Yue Z, Geng X, Wang P, Gan J, Liao B. Effects of space environment temperature on the mechanical properties of carbon fiber/bismaleimide composites laminates. P I Mech Eng G - J Aer. 2017;232:3-16. https://doi.org/10.1177/ 0954410017740382 .

[17] Duan C, Yang Z, Zhang D, Tao L, Wang Q, Wang T. Effect of isomerism on mechanical and tribological properties of thermoplastic polyimide films. Tribol In 2018;21:373-80. https://doi.org/10.1016/j.triboint.2018.01.060.

[18] Shi XW, Lian H, Yan XS, Qi R, Yao N, Li T. Fabrication and properties of polyimide composites filled with zirconium tungsten phosphate of negative thermal expansion. Mater Chem Phys 2016;179:72-9. https://doi.org/10.1016/j.matchemphys. 2016.05.011.

[19] Mekuria TD, Chunhong Z, Yingnan L, El Din Fouad D, Lv K, Yang M, et al. Surface modification of nano-silica by diisocyanates and their application in polyimide matrix for enhanced mechanical, thermal and water proof properties. Mater Chem Phys 2019;225:358-64. https://doi.org/10.1016/j.matchemphys.2018.12.107.

[20] Lee H-G, Kim G-H, Ha C-S. Polyimide/amine-functionalized cellulose nanocrystal nanocomposite films. Mater Today Commun 2017;13:275-81. https://doi.org/10 1016/j.mtcomm.2017.10.010.

[21] Chen Z, Liu S, Yan S, Shu X, Yuan Y, Huang H. Overall improvement in dielectric and mechanical properties of porous graphene fluoroxide/polyimide nanocomposite films via bubble-stretching approach. Mater Des 2017;117:150-6. https://doi. org/10.1016/j.matdes.2016.12.082.

[22] Gao H, Xie F, Liu Y, Leng J. Effects of $\gamma$-radiation on the performances of optically transparent shape memory polyimides with a low glass transition temperature. Polym Degrad Stab 2018;156:245-51. https://doi.org/10.1016/j.polymdegradstab. 2018.09.014.

[23] Okada T, Ishige R, Ando S. Analysis of thermal radiation properties of polyimide and polymeric materials based on ATR-IR Spectroscopy. J Photopolym Sci Tec 2019;29:251-4. https://doi.org/10.2494/photopolymer.29.251.

[24] Wang Q, Zheng F, Wang T. Tribological properties of polymers PI, PTFE and PEEK at cryogenic temperature in vacuum. Cryogenics 2016;75:19-25. https://doi.org/ 10.1016/j.cryogenics.2016.01.001.

[25] Qu C, Hu J, Liu X, Li Z, Ding Y. Morphology and mechanical properties of polyimide films: the effects of UV irradiation on microscale surface. Materials 2017;10:1329. https://doi.org/10.3390/ma10111329.

[26] Hiroyuki S, Ichiro Y. Degradation of mechanical properties of polyimide film exposed to space environment. J Spacecraft Rockets 2009;46:15-21. https://doi.org/ 10.2514/1.31814

[27] Hatakenaka R, Miyakita T, Sugita H, Saitoh M, Hirai T. Development and testing of a zero stitch MLI blanket using plastic pins for space use. Cryogenics 2014;64:121-34. https://doi.org/10.1016/j.cryogenics.2014.02.018.

[28] Sharma GR, Lind C, Coleman MR. Preparation and properties of polyimide nanocomposites with negative thermal expansion nanoparticle filler. Mater Chem Phys 2012;137:448-57. https://doi.org/10.1016/j.matchemphys.2012.09.009.

[29] Kwon J, Kim J, Lee J, Han P, Park D, Han H. Fabrication of polyimide composite films based on carbon black for high-temperature resistance. Polym Compos 2014;35:2214-20. https://doi.org/10.1002/pc.22886.

[30] Wu Y, Chen G, Zhan M, Yang J. High heat resistant carbon fiber/polyimide composites with neutron shielding performance. Prog Org Coat 2019;132:184-90. https://doi.org/10.1016/j.porgcoat.2019.03.047.
[31] Zhao H, Yang C, Li N, Yin J, Feng Y, Liu Y, et al. Electrical and mechanical properties of polyimide composite films reinforced by ultralong titanate nanotubes. Surf Coat Tech 2019;360:13-9. https://doi.org/10.1016/j.surfcoat.2019.01.013.

[32] Wozniak AI, Ivanov VS, Kosova OV, Yegorov AS. Polyimide composites with nanostructured silicon carbide. Orient J Chem 2016;32:2967-74. http://dx.doi.org/ $10.13005 / \mathrm{ojc} / 320616$.

[33] Averina EA, Yegorov AS, Bogdanovskaya MV, Wozniak AI, Zhdanovich OA. Polyimide composite materials containing modified nanostructured boron carbide. Orient J Chem 2018;34:743-9. http://dx.doi.org/10.13005/ojc/340217.

[34] Li X-min, Wu Ju-ying, Tang C-yu, Yuan P, Xing T, Zhang K et al. Thermal Neutron Radiation Shielding and Thermal Properties of B4CP/PI Polyimide Composite Films. J Mater Eng. 2018;46:48-54. https://doi.org/10.11868/j.issn.1001-4381. 2016.001076.

[35] Qiu X, Wang H, Zhou C, Li D, Liu Y, Yan C. Polyimide/kaolinite composite films: Synthesis and characterization of mechanical, thermal and waterproof properties. J Taiwan Inst Chem E 2014;45:2021-8. https://doi.org/10.1016/j.jtice.2014.01.012.

[36] Zhao Y, Qi X, Dong Y, Ma J, Zhang Q, Song L. Mechanical, thermal and tribological properties of polyimide/nano-SiO $\mathrm{S}_{2}$ composites synthesized using an in-situ polymerization. Tribol Int 2016;103:599-608. https://doi.org/10.1016/j.triboint.2016. 08.018.

[37] Liu CW, Qu CY, Han L, Wang DZ, Xiao WB, Hou X. Preparation of carbon fiberreinforced polyimide composites via in situ induction heating. High Perform Polym 2016;9:1027-36. https://doi.org/10.1177/0954008316667789.

[38] Miller L, Gulino D. Aluminum oxide films for thermo-oxidative protection of polyimide-based composites. MRS Proceedings 1993;305:191. https://doi.org/10. 1557/PROC-305-191.

[39] Kiefer RL, Herring K, Wylie BJ, Orwoll RA, Thibeault SA. The effects of UV radiation on several high-performance polyimide composites. Polymer Int 1999;48:1042-5. https://doi.org/10.1002/(SICI)1097-0126(199910)48:10 < 1042::AID-PI266 > 3.0. CO; $2-2$.

[40] Cherkashina NI, Pavlenko VI, Noskov AV. Radiation shielding properties of polyimide composite materials. Radiat Phys Chem 2019;159:111-7. https://doi.org/10 1016/j.radphyschem.2019.02.041.

[41] Pavlenko VI, Cherkashina NI, Yastrebinsky RN. Synthesis and radiation shielding properties of polyimide/Bi2O3 composites. Heliyon. 5; 2019: e01703. https://doi. org/10.1016/j.heliyon.2019.e01703.

[42] Tekin HO, Sayyed MI, Issa SAM. Gamma radiation shielding properties of the hematite-serpentine concrete blended with $\mathrm{WO}_{3}$ and $\mathrm{Bi}_{2} \mathrm{O}_{3}$ micro and nano particles using MCNPX code. Radiat Phys Chem 2018;150:95-100. https://doi.org/10.1016/ j.radphyschem.2018.05.002.

[43] Aghaz A, Faghihi R, Mortazavi S, Haghparast A, Mehdizadeh S, Sina S. Radiation attenuation properties of shields containing micro and Nano $\mathrm{WO}_{3}$ in diagnostic Xray energy range. Int J Radiat Res 2016;14:127-31. https://doi.org/10.18869/ acadpub.ijrr.14.2.127.

[44] Dong Y, Shuquan C, Zhang H-X, Ren C, Kang B, Dai M-Z, et al. Effects of $\mathrm{WO}_{3}$ Particle Size in $\mathrm{WO}_{3}$ /Epoxy Resin Radiation Shielding Material. Chin Phys Lett. 2012;29:108102. https://doi.org/10.1088/0256-307X/29/10/108102.

[45] Xu X, Yazdi MAP, Salut R, Cote JM, Billard A, Martin N. Structure, composition and electronic transport properties of tungsten oxide thin film sputter-deposited by the reactive gas pulsing process. Mater Chem Phys 2018;205:391-400. https://doi.org/ 10.1016/j.matchemphys.2017.11.048.

[46] Aird A, Domeneghetti MC, Mazzi F, Tazzoli V, Salje EKH. Sheet superconductivity in $\mathrm{WO}_{3-\mathrm{x}}$ crystal structure of the tetragonal matrix. J. Phys. Condens. Matter. 1998:;10:L569. https://doi.org/10.1088/0953-8984/10/33/002.

[47] Cazzanelli E, Vinegoni C, Mariotto G, Kuzmin A, Puransà J. Low-temperature polymorphism in tungsten trioxide powders an its dependence on mechanical treatments. J. Solid State Chem. 1999;143:24-32. https://doi.org/10.1006/jssc. 1998.8061

[48] Pavlenko VI. Cherkashina NI synthesis of hydrophobic filler for polymer composites. Int J Eng Techn 2018;7:493-5. https://doi.org/10.14419/ijet.v7i2.23.15341.

[49] Eskin DI, Voropayev SN, Dorokhov IN, Artemyev VK. The research of jet vortex mills. Particul Sci Technol 1997;15:88-92. https://doi.org/10.1080/ 02726359708906715.

[50] Phat C, Li H, Lee D-U, Moon BK, Yoo Y-B, Lee C. Characterization of Hericium erinaceum powders prepared by conventional roll milling and jet milling. J Food Eng 2015;145:19-24. https://doi.org/10.1016/j.jfoodeng.2014.08.001.

[51] Kato H, Nakamura A, Shimizu M, Banno H, Kezuka Y, Matsubara K, et al. Acceleration of dispersing calcium carbonate particle in aqueous media using jet milling method. Colloid Surface A 2017;520:570-9. https://doi.org/10.1016/j. colsurfa.2017.02.010

[52] Radican K, Bozhko SI, Vadapoo S-R, Ulucan S, Wu H-C, McCoy A, et al. Oxidation of W(110) studied by LEED and STM. Surf. Sci 2010;604:1548-51. https://doi.org/10 1016/j.susc.2010.05.016.

[53] Marghalani HY. Effect of filler particles on surface roughness of experimental composite series. J Appl Oral Sci 2010;18:59-67. https://doi.org/10.1590/S167877572010000100011.

[54] Morankar S, Mandal M, Kourra N, Williams MA, Mitra R, Srirangam P. X-Ray tomography study on porosity and particle size distribution in in situ $\mathrm{Al}_{-4.5} \mathrm{Cu}_{-5} \mathrm{TiB}_{2}$ semisolid rolled composites. JOM 2019;2019:1-9. https://doi.org/10.1007/ s11837-019-03385-z.

[55] Pukanszky B, Vörös G. Mechanism of interfacial interactions in particulate filled composites. Compos Interface 1993;1:411-27. https://doi.org/10.1163/ $156855493 X 00266$

[56] Takeda T, Shindo Y, Watanabe S, Narita F. Three-dimensional stress analysis of cracked satin woven carbon fiber reinforced/polymer composites under tension at cryogenic temperatures. Cryogenics 2012;52:784-92. https://doi.org/10.1016/j. 
cryogenics.2012.09.002.

[57] Atli-Veltin B. Cryogenic performance of single polymer polypropylene composites. Cryogenics 2018;90:86-95. https://doi.org/10.1016/j.cryogenics.2018.01.009.

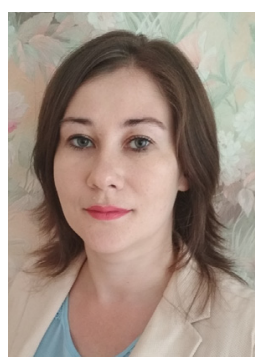

Cherkashina N.I. was born in Belgorod, Russia in 1988. She received the Candidate of Engineering Sciences in condensed matter physics from the Belgorod State National Research University, Belgorod, Russia in 2013. Since 2013 she has been a Research Assistant with the Belgorod State Technological University named after V.G. Shoukhov (BSTU).

Since 2013 she has been an associate Professor with the Radiation monitoring laboratory. Her research interest includes the radiation solid-state physics and space materials science. She is the author of two monographs, more than 100 articles, and 10 patents.

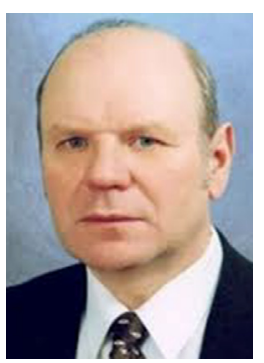

Pavlenko V.I. was born in Belgorod, Russia in 1949. He received the Candidate of Chemical Sciences in Physical chemistry from the Leningrad Institute of Technology, Saint Petersburg, Russia, in 1978 and the Doctor of Engineering Sciences in solid state physics from Moscow State University of Electronics and Mathematics, Moscow, Russia, in 1997.

Since 2005 he has been a director of the Chemical Technology Institute, BSTU, Russia. His research interest includes the radiation solid-state physics and space materials science. He is the author of five books, more than 200 articles, and 18 patents. He is an Honored Inventor of the Russian Federation.

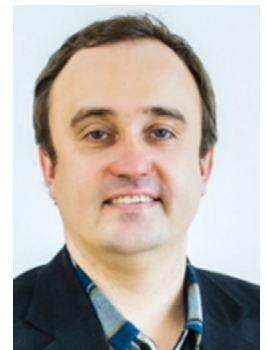

Noskov A.V. was born in Shevchenko, Kazakhstan in 1979. He received the Candidate of physical and mathematical sciences in Theoretical physics from the Belgorod State University, Belgorod, Russia, in 2004 and the Doctor of physical and mathematical sciences in Physics of the atomic nucleus and elementary particles from Skobeltsyn Research Institute of Nuclear Physics of Lomonosov Moscow State University, Moscow, Russia, in 2010.

Since 2017 he has been a head of the Department of Theoretical and Mathematical Physics, BSU, Russia. He is the author of more than 100 articles. 